\title{
Effects of Labetalol on In Vitro Preparations of the Trachea and Lung Strips and on Ventilation Overflow In Vivo in Guinea Pigs
}

\author{
Haruko KAMEDA \\ Department of Pharmacology. Faculty of Pharmaceutical Sciences. \\ Higashi-Nippon Gakuen University. Kanazawa 1757, Ishikari-Tobetsu. \\ Hokkaido 061-02, Japan \\ Accepted December 1. 1986
}

\begin{abstract}
The responses of guinea pig central and peripheral airways to labetalol (both $\alpha$-and $\beta$-adrenoceptor blocker with intrinsic sympathomimetic activity) were studied using in vivo and in vitro preparations of the trachea and lung strips. The ventilation overflow enhanced by infusion of histamine in anesthetized guinea pigs was much more aggravated by labetalol and propranolol. The $\beta$-adrenoceptor blocking potency of labetalol and propranolol was not significantly different between the in vitro tracheal preparations and the lung strips. Isoproterenol and salbutamol relaxed the tracheal preparations more markedly than they did the lung strips. Histamine and acetylcholine contracted the lung strips more remarkably than they did the trachea. Labetalol relaxed the trachea more markedly than it did the lung strips by its intrinsic sympathomimetic activity. These results suggest that the peripheral airways are more sensitive to constrictors and the central airways are more sensitive to relaxants such as $\beta$-stimulants, and that the different responsiveness between the two airways to labetalol and histamine might have produced the different in vivo observations.
\end{abstract}

Labetalol is an antihypertensive agent which possesses $\alpha_{1}, \beta_{1}, \beta_{2}$-adrenoceptor blocking actions (1-3) and intrinsic sympathomimetic ( $\beta$-receptor partial agonist) activity. ISA (4-7), and has higher selectivity to $\beta$ - than to $\alpha$-receptors (1). Betaadrenoceptor blocking agents such as propranolol. which have been used for angina, hypertension and cardiac arrhythmias, have the risk of aggravating bronchoconstriction (8).

In the previous study (9), we found that labetalol produced a marked alleviation of asthmatic dyspnea induced by inhaling histamine solution in guinea pigs, while propranolol aggravated it; and from experiments using isolated tracheal preparations, it was suggested that this alleviative effect of labetalol might have been produced by its $\alpha$ adrenoceptor blocking action and by $\beta$ adrenoceptor partial agonist action (9). However, as the sizes of the aerosols which were made by the handspray were larger than $5 \mu \mathrm{m}$ (9), which has been reported to be too large to reach the peripheral airways (alveoli and bronchioles) (10), it was thought that histamine aerosols might not have reached the peripheral airways.

In order to investigate the effect of labetalol on the peripheral airways in guinea pigs, the present investigation was undertaken to study the effect of labetalol on ventilation overflow, and a comparison was made of the responses of isolated lung parenchymal preparations and tracheal preparations to labetalol. constrictors and relaxant drugs.

\section{Materials and Methods}

Drugs: Drugs used were as follows: diphenhydramine hydrochloride (Kowa Co., Ltd.), histamine dihydrochloride (Wako Pure Chemicals), methacholine chloride (Wako Pure Chemicals), dl-isoproterenol hydrochloride ( $\mathrm{ICl}$ Pharmaceuticals), salbutamol sulfate (Kanto Chemical Co.), dl-propranolol 
hydrochloride ( $\mathrm{Cl}$ Pharmaceuticals) and phentolamine mesylate (Ciba Geigy). Labetalol hydrochloride was a gift from the Shin-Nippon Jitsugyo Co., Ltd.

Ventilation overflow (VO): Guinea pigs of either sex (weight about $500 \mathrm{~g}$ ) were anesthetized with urethane $(1.2-1.5 \mathrm{~g} / \mathrm{kg}$, i.p.). The method used for the measurement of ventilation overflow is the modified method of Konzett and Rössler (11). The animals were tracheotomized and artificially respired with a respirator (Harvard Rodent Respirator. Model 680) at a frequency of 60 cycles $/ \mathrm{min}$ with an air volume of 7 to $10 \mathrm{ml} / \mathrm{kg}$ at a load pressure of $10 \mathrm{cmH}_{2} \mathrm{O}$. Bilateral phrenicotomy was carried out to eliminate phrenic reflexes. The Harvard Rodent Respirator was connected to a three-way tube, of which one lead was connected to the trachea up to the bifurcation of bronchi, and the other was connected to a bronchospasm transducer (Ugo Basile, Catalog No. 7020) to measure the volume of overfiow of inspiration (the ventilation overflow). The external jugular vein was cannulated for continuous infusion of histamine dihydrochloride solution at a rate of $5 \mu \mathrm{g} / 0.25 \mathrm{ml}$ per minute with a peristaltic pump (Perpex pump No. 10200. LKB). At about $1 \mathrm{~min}$ after the infusion of histamine solution, an increase of ventilation overflow was observed. When the ventilation overflow enhanced by the infusion of histamine became steady, labetalol or other drugs were administered intravenously from the femoral vein at a volume of $0.5 \mathrm{ml} / \mathrm{kg}$. Phentolamine, propranolol and diphenhydramine were dissolved in saline just before use. The systemic blood pressure was measured from the right carotid artery by a pressure transducer (San-ei Instruments. MPU-0.5). Heart rate was monitored by an electrocardiograph using a lead II attachment. All signals were recorded on a polygraph (San-ei Instruments, 141-6) or on an inkwriting recorder (Nihon Kohden, AD2-22).

Preparation of guinea pig tracheal and lung parenchymal strips: Male and female guinea pigs weighing about $500 \mathrm{~g}$ were stunned and bled. The trachea, lung and heart were dissected en bloc and placed in ice-cold Tyrode's solution. The trachea was mounted according to the technique outlined by Takagi et al. (12), suspended in an organ bath containing $37^{\circ} \mathrm{C}$ Tyrode's solution, and then continuously gassed with $95 \% \mathrm{O}_{2}$ and $5 \% \mathrm{CO}_{2}$. Lung strips $(2 \times 2 \times 15-20 \mathrm{~mm})$ were dissected from a lower lobe as described for cat strips by Lulich et al. (13) and suspended in a bath similar to that used for the trachea. Changes in the tone of the tracheal and lung parenchymal strip preparations were recorded with a force displacement transducer (San-ei Instruments, 45071) and a recorder (Hitachi Ltd., 056). The preparations were allowed to equilibrate for two hours under a resting load of 0.5 to $0.8 \mathrm{~g}$ for the trachea and 0.2 to $0.3 \mathrm{~g}$ for the lung strips. Drugs were prepared freshly on the day of use and diluted with Tyrode's solution to the appropriate concentration just before use.

Invasion of histamine aerosol into the guinea pigs' airways: In order to confirm the degree of invasion of histamine aerosol into the airways of the guinea pigs, two guinea pigs were placed in a desicator having a side hole and a capacity of 8 liters and allowed to inhale Evan's blue aqueous solution at a concentration of $5.0 \mathrm{~g} / 100 \mathrm{ml}$ through the side hole by using a handspray (Cannon KK, more than $99 \%$ of the sizes of the aerosols were larger than $5, \mu \mathrm{m}$ ) under the same conditions as those used for histamine-induced asthma as reported previously (9). The total amount was approximately $2.7 \mathrm{ml} /$ animal. After 5 minutes, the guinea pigs were removed from the desiccator and anesthetized with sodium pentobarbital (50 mg/kg. i.p.). Then, their chests were opened and the sites showing the presence of Evan's blue dye in the airways were examined. The same experiment was performed with an ultrasonic nebulizer (Omuron KK, the sizes of aerosols were 1 to $5 \mu \mathrm{m})$.

\section{Results}

1. Effects of labetalol, propranolol, phentolamine and diphenhydramine on the ventilation overflow (VO) enhanced by histamine infusion

Figure 1 shows the increase of histamineenhanced $V O$ by intravenous administration of labetalol $(0.1 \mathrm{mg} / \mathrm{kg}, 0.3 \mathrm{mg} / \mathrm{kg}$ and 1.0 $\mathrm{mg} / \mathrm{kg}$ ) and propranolol $(0.1 \mathrm{mg} / \mathrm{kg}$ and 1.0 $\mathrm{mg} / \mathrm{kg}$ ). The number of cases at each dose 
was three to five. The infusion of histamine at a rate of $5 \mu \mathrm{g} / 0.25 \mathrm{ml}$ per minute produced a slight increase of heart rate. A decrease of systemic blood pressure occurred transiently at the beginning of infusion, and then a slight decrease of blood pressure was maintained during the infusion of histamine solution. At less than $0.03 \mathrm{mg} / \mathrm{kg}$, i.v., of labetalal, there was no clear increase of histamine-enhanced $V O$ observed. In eleven cases of labetalol administered at doses of more than $0.1 \mathrm{mg} / \mathrm{kg}$. i.v. $(n=12)$, there was an increase of $V O$, as shown in Fig. 1., although only one case showed a decrease of histamine-enhanced $\mathrm{VO}$ by administration of labetalol at the doses of $0.1 \mathrm{mg} / \mathrm{kg}$ and 1.0 $\mathrm{mg} / \mathrm{kg}$. Labetalol $(0.1 \mathrm{mg} / \mathrm{kg}$, i.v. and 1.0 $\mathrm{mg} / \mathrm{kg}$. i.v.) decreased the heart rate and the systemic blood oressure. Propranolol produced an increase of histamine-enhanced Vo
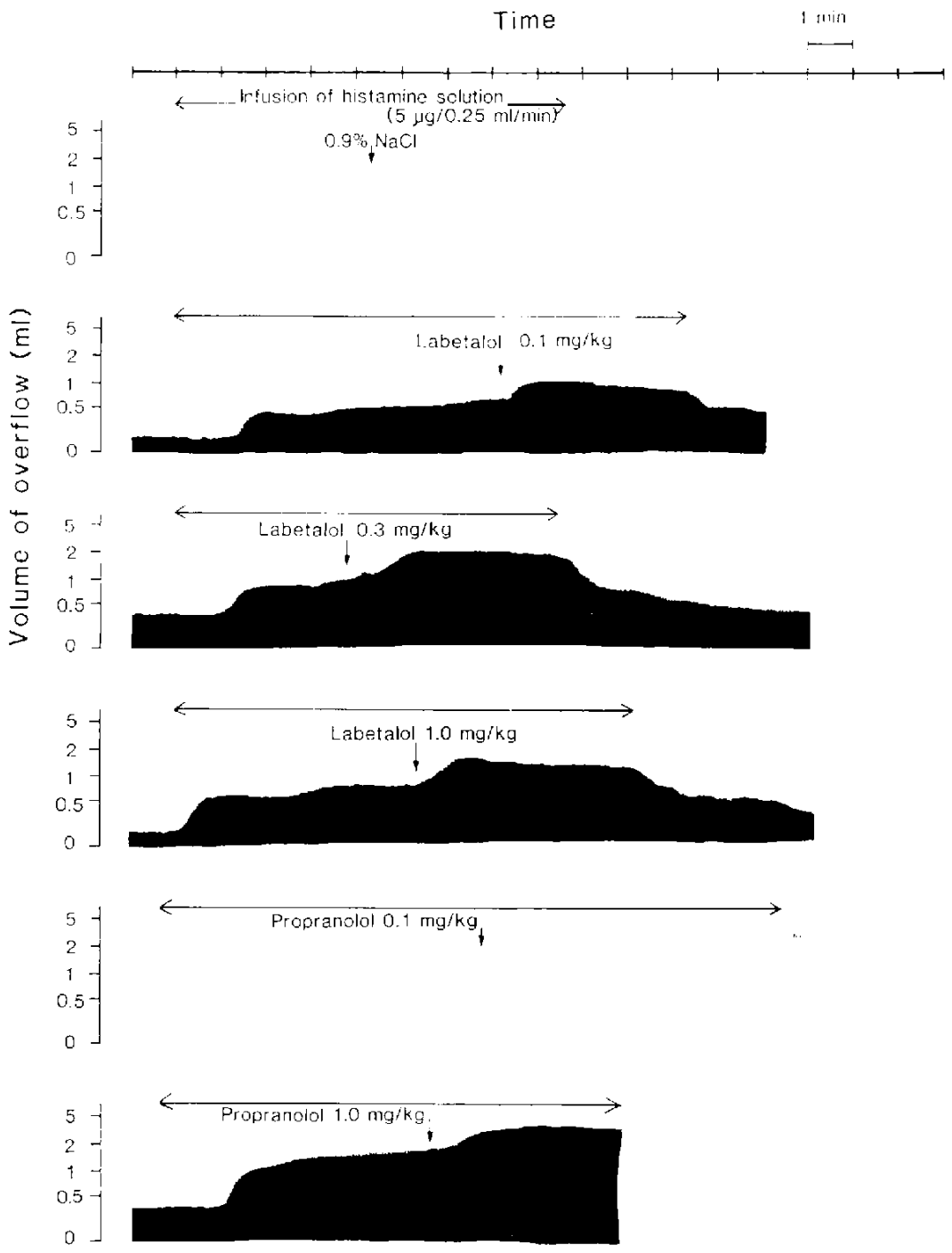

Fig. 1. Effects of labetalol and propranolol on ventilation overflow enhanced by infusion of histamine solution in anesthetized guinea pigs. Histamine solution was infused from the jugular vein at a rate of $5 \mu \mathrm{g} / 0.25 \mathrm{ml}$ per minute. Drugs and $0.9 \% \mathrm{NaCl}$ aqueous solution were administered from the femoral vein at a volume of $0.5 \mathrm{ml} / \mathrm{kg}$. Verticals: Volume of overflow of inspiration. 
and a decrease in the heart rate and systemic blood pressure at the doses of $0.1 \mathrm{mg} / \mathrm{kg}$, i.v. $(n=4)$ and $1.0 \mathrm{mg} / \mathrm{kg}$, i.v. $(n=3)$. Propranolol at the dose of $1.0 \mathrm{mg} / \mathrm{kg}$. i.v. caused a marked decrease in the heart rate and produced the death of two cases during the infusion of histamine solution as shown in Fig. 1. This result was thought to be caused by the inhibitory effect of propranolol on the heart. Phentolamine produced a decrease of histamine-enhanced $\mathrm{VO}$ at the doses of 0.1 $\mathrm{mg} / \mathrm{kg}$. i.v. $(n=3)$ and $1.0 \mathrm{mg} / \mathrm{kg}$. i.v. $(n=3)$ (Fig. 2). Phentolamine at the dose of $1.0 \mathrm{mg} /$ $\mathrm{kg}$ produced irregular respiration following the decrease of $V O$ in all cases. Phentolamine at $1.0 \mathrm{mg} / \mathrm{kg}$, i.v., did not change the systemic blood pressure, but slightly decreased the heart rate. It was considered that the spontaneous respiration might have been stimulated by the administration of phentolamine. The decrease of $V O$ by phentolamine was considered to be caused by its antihistaminic action and by $\alpha$-adrenoceptor blocking action on the respiratory organs. Diphenhydramine also produced a decrease of histamineenhanced VO at the dose of $0.3 \mathrm{mg} / \mathrm{kg}$, i.v. $(n=3)$, and the inhibitory effect on histamineenhanced VO was larger at one hour after administration of diphenhydramine than immediately after it (Fig. 2). Diphenhydramine at the dose of $0.3 \mathrm{mg} / \mathrm{kg}$ following the infusion of histamine solution changed neither the blood pressure nor the heart rate. 2. Tracheal and lung parenchymal preparations

2-1. $\beta$-Adrenoceptor blocking action: Table 1 shows the $\beta$-adrenoceptor blocking potencies of labetalol and propranolol on tracheal preparations and lung parenchymal strips. The $\mathrm{pA}_{2}$ values and slopes were calculated by the method of Arunlakshana and Schild (14). The $\mathrm{pA}_{2}$ values of labetalol

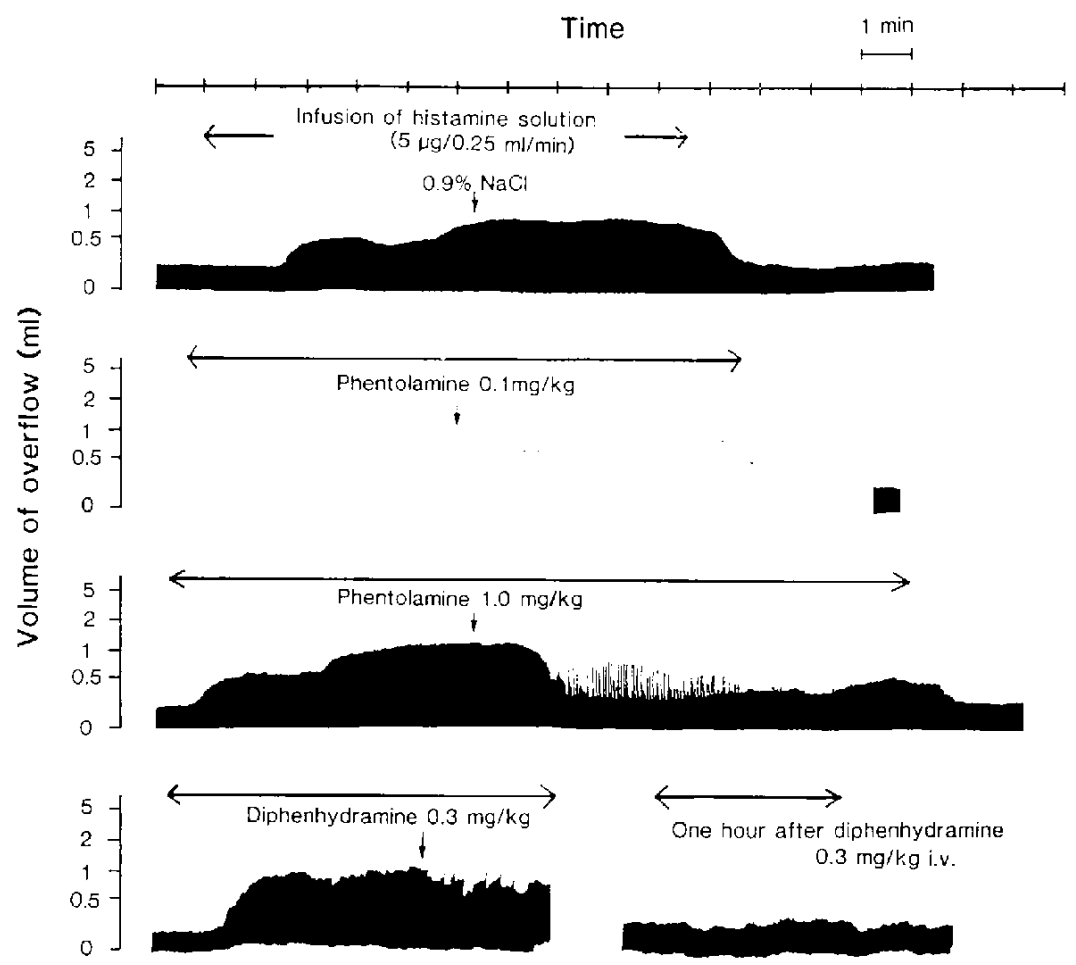

Fig. 2. Effects of phentolamine and diphenhydramine on ventilation overflow enhanced by infusion of histamine solution in anesthetized guinea pigs. Histamine solution was infused from the jugular vein at a rate of $5, \mu \mathrm{g} / 0.25 \mathrm{ml}$ per minute. Drugs and $0.9 \% \mathrm{NaCl}$ aqueous solution were administered from the femoral vein at a volume of $0.5 \mathrm{ml} / \mathrm{kg}$. Verticals: Volume of overflow of inspiration. 
Table 1. Comparison of $\beta$-adrenoceptor blocking activities of labetalol and propranolol in isolated tracheal preparations and lung strips of guinea pigs

\begin{tabular}{|c|c|c|c|c|c|c|c|c|}
\hline \multirow{3}{*}{ Preparation } & \multirow{3}{*}{$\begin{array}{l}\text { Type of } \\
\text { receptor }\end{array}$} & \multirow{3}{*}{ Agonist } & \multicolumn{6}{|c|}{ Antagonist activity } \\
\hline & & & & Labe & & & Propra & \\
\hline & & & $n$ & $\mathrm{pA}_{2}$ & slope & $\mathrm{n}$ & $\mathrm{pA}_{2}$ & slope \\
\hline Trachea & $\beta_{2}$ & Isp & 7 & $\begin{array}{c}7.67 \\
(0.31)\end{array}$ & $\begin{array}{c}0.81 \\
(0.10)\end{array}$ & 4 & $\begin{array}{c}8.53 \\
(0.19)\end{array}$ & $\begin{array}{c}0.87 \\
(0.15)\end{array}$ \\
\hline Lung & $\beta_{2}$ & Isp & 4 & $\begin{array}{c}7.78 \\
(0.09)\end{array}$ & $\begin{array}{r}1.25^{*} \\
(0.73)\end{array}$ & 4 & $\begin{array}{c}8.67 \\
(0.24)\end{array}$ & $\begin{array}{c}0.97 \\
(0.25)\end{array}$ \\
\hline
\end{tabular}

Each value of $\mathrm{pA}_{2}$ and slope, which was calculated by the method of Arunlakshana and Schild, shows the mean together with a standard error of the mean in parentheses. $n$ : number of experiments. ${ }^{*} P<0.05$. significantly different from the tracheal preparations.

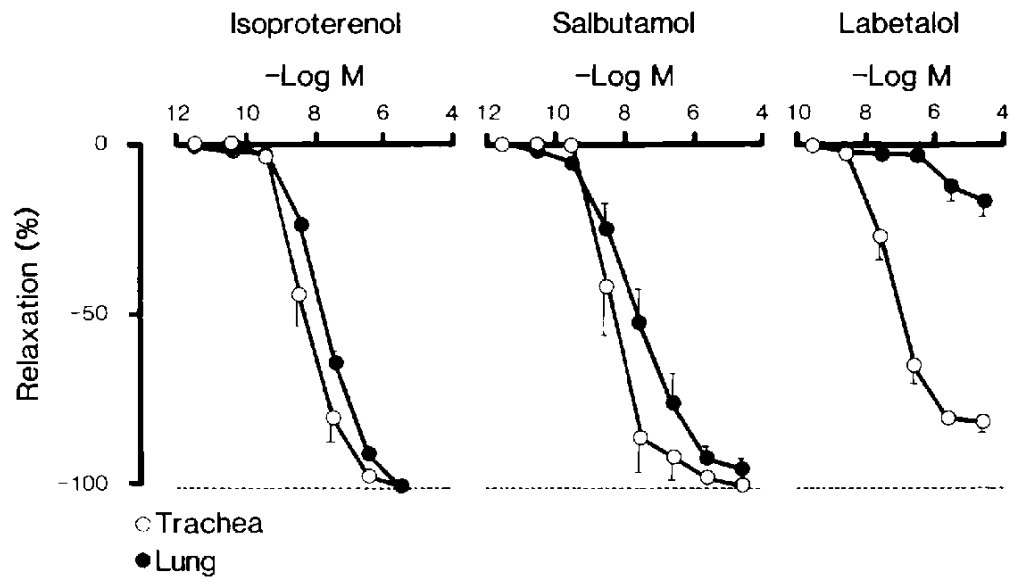

Fig. 3. Concentration-response curves showing the relaxing activity of isoproterenol, salbutamol and labetalot on isolated tracheal preparations and lung strips in guinea pigs.

and propranolol were slightly larger in the lung parenchymal strips than in the tracheal preparations, but the difference was not significant between the two preparations. The slopes of labetalol and propranolol were slightly larger in the lung strips than in the tracheal preparations.

2-2. Bronchodilating action of sympathomimetics and labetalol: Figure 3 shows the cumulative relaxing responses of the tracheal preparations and the lung parenchymal strips to isoproterenol (non-selective $\beta_{1}, \beta_{2}{ }^{-}$ agonist), salbutamol (selective $\beta_{2}$-agonist) and labetalol $\left(\alpha_{1}, \beta_{1}, \beta_{2}\right.$-adrenoceptor blocker, which possesses intrinsic sympathomimetic activity). In the cases of labetalol and salbutamol, the ratios to the maximal relaxing response of isoproterenol were calculated by administration of isoproterenol after the cumulative dose response of labetalol and salbutamol was completed. The relaxing responses to these drugs were more sensitive in the tracheal preparations than in the lung strips. The relaxing response to labetalol was more pronounced in the trachea than in the lung strips, which suggested that in the lung parenchymal strips, the relaxing action by intrinsic sympathomimetic activity of labetalol was restrained and that there was a marked difference between the two kinds of preparations.

2-3. Contractile responses to histamine and acetylcholine: Figure 4 shows the contractile responses of the tracheal preparations and the lung parenchymal strips to histamine and acetylcholine. It was found that the 
contractile responses to histamine and acetylcholine were more sensitive in the lung parenchymal strips than in the tracheal preparations. Table 2 shows the $\mathrm{pD}_{2}$ values (negative log of molar concentration of ED50) and intrinsic activity (i.a.) obtained from the dose-response curves of these drugs. The $\mathrm{pD}_{2}$ values of isoproterenol, salbutamol and labetalol were significantly larger in the tracheal preparations than in the lung strips. This means that the sensitivity of relaxing response was more sensitive in the tracheal preparations than in the lung strips. Intrinsic activity (i.a.) of labetalol was 0.80 in the tracheal preparations and 0.15 in the lung strips. It was found that the lung strips were much more sensitive to constrictor agents (histamine and acetylcholine) than were the tracheal preparations.

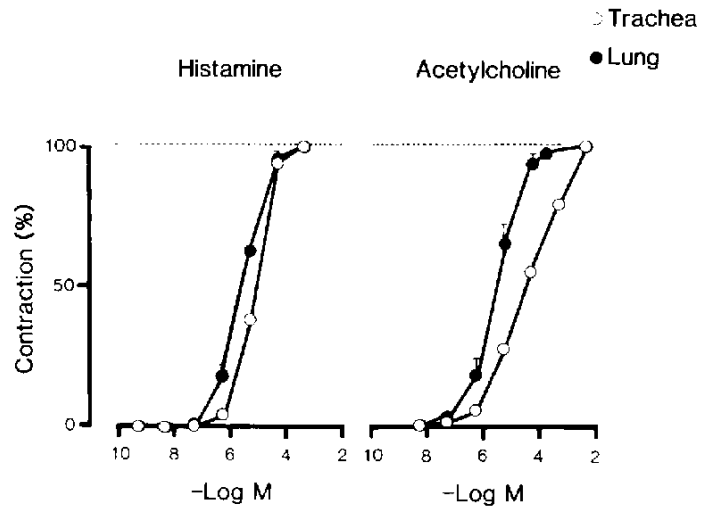

Fig. 4. Concentration-response curves showing the contractile activity of histamine and acetylcholine on isolated tracheal preparations and lung strips in guinea pigs.

\section{Invasion of aerosol of Evan's blue aqueous solution into guinea pig airways}

Evan's blue aqueous solution was administered to guinea pigs by inhalation using the handspray introduced in the previous study (9), and the sites where Evan's blue aerosol reached the guinea pig airways were confirmed. Evan's blue was found in the nasal and oral cavities, pharynx, larynx, trachea, bronchi and esophagus, but was found neither in the lung parenchyma nor in the bronchioles. When the solution was administered by inhalation with an ultrasonic nebulizer, the lung was stained in blue in places, and it was found that the aerosol had reached the deep part of the lung. Therefore, it was confirmed that the aerosol applied with the handspray reached mainly the upper part of the airways (Figure is not shown).

\section{Discussion}

We have demonstrated that labetalol alleviated asthma induced by administering histamine aerosols by inhalation in guinea pigs, but that propranolol aggravated it (9).

However, the diameters of more than $99 \%$ of the aerosol particles, which were made by the handspray used in the previous study (9), were larger than $5 \mu \mathrm{m}$. It is thought that aerosols can reach the oral cavity and pharynx at 10 to $30 \mu \mathrm{m}$, the larynx and trachea at 5 to $10 \mu \mathrm{m}$ and the bronchioles and alveoli at 1 to $3 \mu \mathrm{m}$ in size (10). From the experiments using Evan's blue solution, it was confirmed that almost all the aerosols made by the handspray were observed in the upper part of the airways (from the oral cavity to the bronchi) and that no aerosols were recognized

Table 2. Comparative responses of tracheal preparations and lung strips to isoproterenol, salbutamol, labetalol, histamine and acetylcholine

\begin{tabular}{|c|c|c|c|c|c|c|c|}
\hline \multirow{3}{*}{ Isoproterenol } & \multicolumn{4}{|c|}{ Tracheal preparation } & \multicolumn{3}{|c|}{ Lung strip } \\
\hline & \multirow{2}{*}{$\begin{array}{l}n \\
7\end{array}$} & \multicolumn{2}{|c|}{$\mathrm{pD}_{2}$} & \multirow{2}{*}{$\begin{array}{r}\text { i.a. } \\
1.00\end{array}$} & \multirow{2}{*}{$\begin{array}{l}n \\
11\end{array}$} & $\mathrm{pD}_{2}$ & \multirow[t]{2}{*}{ i.a. } \\
\hline & & 8.12 & \pm 0.18 & & & $7.68^{*} \pm 0.11$ & \\
\hline Salbutamol & 3 & 8.37 & \pm 0.29 & $0.99 \pm 0.01$ & 6 & $7.38^{*} \pm 0.15$ & \pm 0.02 \\
\hline Labetalol & 6 & 7.28 & \pm 0.16 & $0.80 \pm 0.02$ & 5 & $5.89^{* * *} \pm 0.04$ & $0.19 * * \pm 0.05$ \\
\hline Histamine & 41 & $5.10^{*}$ & \pm 0.07 & 1.00 & 5 & $5.56 \pm 0.04$ & 1.00 \\
\hline Acetylcholine & 12 & $4.34^{*}$ & \pm 0.08 & 1.00 & 8 & \pm 0.15 & 1.00 \\
\hline
\end{tabular}

Each value is the mean \pm S.E. $n$ : number of experiments. ${ }^{*} P<0.05,{ }^{* *} P<0.001$, significantly different between the tracheal preparations and the lung strips and are marked over the smaller values. which show lower sensitivity between the tracheal preparations and the lung strips. 
in the peripheral airways. Therefore, it was considered that the results of histamineinduced asthma reported previously (9) reflected the response of the central airways (trachea and bronchi) to histamine.

It has been reported that the peripheral airways contain mainly small airways and alveoli which contribute to compliance changes. On the other hand, the central airways contribute mostly to resistance or bronchoconstriction (15). In the present study. since the tracheal cannula was inserted up to the bifurcation of bronchi in anesthetized guinea pigs, it was considered that the changes of ventilation overflow reflected the responses of the bronchi and peripheral airways. Phentolamine and diphenhydramine decreased the histamineenhanced ventilation overflow. The author and coworkers reported (9) that phentolamine has an antihistaminic action. It has been demonstrated that the inhibitory effect of phentolamine on the exercise-induced asthma is not caused by an antihistaminic action, but by an $\alpha$-adrenoceptor blocking action (16). Both $\alpha_{1}$ - and $\alpha_{2}$-subtypes might be present in airway smooth muscle (17). It has been reported that in animal studies, large-airway responses are mediated by postsynaptic $\alpha_{2}$-receptors and not by $\alpha_{1}$ receptors. On the other hand, peripheral airways have a high density of $\alpha_{1}$-receptors (18). Therefore, it is thought that phentolamine may have inhibitory effects both on the $\alpha_{1}$-adrenoceptor contractile responses in peripheral airways and on the postsynaptic $\alpha_{2}$-adrenoceptor contractile responses in large airways. Labetalol showed the same type of aggravation of histamine-enhanced ventilation overflow as that seen in propranolol. The author and coworkers reported (9) that labetalol exerted not only an $\alpha$ blocking action but also an antihistaminic action, since labetalol in high concentration also shifted the histamine dose-response curve parallel to the right, as seen with phentolamine and diphenhydramine. However, in the experiments of ventilation overflow, labetalol did not show this inhibitory effect. The present result of labetalol suggested the possibility that the responses of the central and peripheral airways to some drugs might be different.

To compare the effect of drugs on the central and peripheral airways in vitro, the responses of the isolated tracheal and lung parenchymal preparations in guinea pigs were examined. From the $\mathrm{pA}_{2}$ values of labetalol and propranolol to the doseresponse curves of isoproterenol on the central and peripheral airways in guinea pigs, it was found that the $\beta$-adrenoceptor blocking potencies of labetalol and propranolol were slightly more potent in the Jung than in the trachea, but they were not significantly different in either preparation. These results were consistent with the observations in cats (13) and in guinea pigs (19). Lulich et al. (13) reported that propranolol was equipotent in inhibiting isoproterenol relaxations in lung strips and in the trachea in cats. Anderson et al. (19) demonstrated that the inhibitory effect of propranolol on the response of epinephrine was not different between lung strips and the trachea in guinea pigs.

On the other hand, it was found that $\beta$ receptor agonists such as isoproterenol. salbutamol and labetalol were more potent in tracheal preparations than in lung parenchymal strips. Especially, the relaxation by labetalol was much more remarkable in the trachea than in the lung strips. The constrictors histamine and acetylcholine were more sensitive in the lung strips than in the tracheal preparations. Therefore, it was confirmed that in guinea pigs, the peripheral airways were more sensitive to constrictor agents such as histamine and acetylcholine and that the central airways were more sensitive to relaxants such as $\beta$-adrenoceptor stimulants. These results correspond to the reports by Anderson et al. (19) who reported that in guinea pigs, the peripheral airways were more sensitive to constrictor agents such as histamine and acetylcholine than were the central airways, and that the spasmolytic agents such as adrenaline, salbutamol and terbutaline were more ineffective in lung strips. Based on these findings, it was reported that lung preparations possess several potential contractile elements: i.e., bronchiolar and vascular smooth muscles (13) and alveolar interstitial myofibroblasts (20). Especially, the response of the lung 
strips to the drugs which have an effect on vascular smooth muscles is thought to be related to the vascular smooth muscles ( 21 . 22).

It is concluded that the above effects might have caused the difference in the results of labetalol in the two in vivo experiments (the result of the previous study (9) using the handspray and that of the experiments of ventilation overflow) in guinea pigs. Evaluation of the overall pharmacological actions of drugs such as labetalol on the respiratory organs in vitro showed the mode by studying not only the response of tracheal preparations (central airway) but also the response of lung preparations (peripheral airways).

Acknowledgements: | would like to thank Professar Tsuneyoshi Tanabe and Associate Professor Yoshio Monma, Higashi Nippon Gakuen University, for their constant encouragement throughout these studies, and I would also like to thank the Shinnippon Jitsugyo Co.. Ltd., for the supply of labetaiol hydrochloride.

\section{References}

1 Brittain, R.T. and Levy, G.P.: A review of the animal pharmacology of labetalol, a combined $\alpha$ - and $\beta$-adrenoceptor-blocking drug. Br. J. Clin. Pharmacol. 3, Supp. 681-694 (1976)

2 Farmer, J.B., Kennedy, I., Levy, G.P. and Marshall, R.J.: Pharmacology of AH 5158: a drug which blocks both $\alpha$-and $\beta$-adrenoceptors. Br. J. Pharmacol. 45, 660-675 (1972)

3 Blakeley, A.G. and Summers, R.J.: The pharmacology of labetalol, an $\alpha$ - and $\beta$-adrenoceptor blocking agent. Gen. Pharmacol. 9, 399-402 (1978)

4 Carpenter, J.R.: Intrinsic activity of labetalol on guinea-pig isolated trachea. J. Pharm. Pharmacol. 33, 806-807 (1981)

5 Carey, B. and Whalley, E.T.: Labetalol possesses $\beta$-adrenoceptor agonist action on the rat isolated uterus. J. Pharm. Pharamacol. 31, 791P (1979)

6 Katano, Y., Takeda, K., Nakagawa, Y., Hashimoto, T., Otorii, T. and Imai, S.: Alpha- and beta-adrenoceptor blocking actions of labetalol and effects on the myocardial function, coronary circulation and myocardial energy metabolism. Folia Pharmacol. Japon. 74, 819-832 (1978) (Abs. in English)

7 Kameda, H., Monma, Y. and Tanabe, T.: Studies on the relaxing effects of labetalol on tracheal muscles in guinea pigs: Second report, the mechanism of action. Japan. J. Pharmacol. 29, Supp. 78P (1979)

8 Skinner, C., Gaddie, J. and Palmer, K.N.V.: Comparison of intravenous AH 5158 (ibidomide) and propranolol in asthma. Br. Med. J. 2, 59-61 (1975)

9 Kameda, H., Monma, Y, and Tanabe, T.: A study on the mechanism of the antihistaminic effect of labetalol on experimental histamine-induced asthma. Folia Pharmacol. Japon. 87, 313-321 (1986) (Abs. in English)

10 Sato, Y.: Medical aerosology and the world situation: inhalational therapy by nebulizer etc. Japan. Med. J. 2793, 29-34 (1977)

11 Konzett, $H$. and Rössler, R.: Versuchsanordnung zu Untersuchungen an der Bronchialmuskulatur. Arch. Exp. Path. Pharmakol. 195, 71-74 (1940)

12 Takagi, K., Takayanagi, I. and Fujie, K.: Chemicopharmacological studies on antispasmodic action on tracheal muscle. Chem. Pharm. Bull. (Tokyo) 6, 716-720 (1958)

13 Lulich, K.M., Mitchell, H.W. and Sparrow, M.P.: The cat lung strip as an in vitro preparation of peripheral airways: a comparison of betaadrenoceptor agonists, autacoids and anaphylactic challenge on the lung strip and trachea. Br. J. Pharmacol. 58, 71-79 (1959)

14 Arunlakshana, O. and Schild, H.O.: Some quantitative uses of drug antagonists. Br. J. Pharmacol. 14, 48-58 (1959)

15 Burns, J.W. and Doe, J.E.: A comparison of drug-induced responses on rat tracheal, bronchial, and lung strip in vitro preparations. $B$ r. J. Pharmacol. 64, 71-74 (1978)

16 Gross, G.N., Souhrada, J.F. and Farr, R.S.: The longterm treatment of an asthmatic patient using phentolamine. Chest 66, 397-401 (1974)

17 Barnes, P.J., Skoogh, B.E., Nadel, J.A., Roberts,

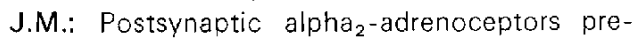
dominate over alpha,-adrenoceptors in canine tracheal smooth muscle and mediate tracheal smooth muscle and mediate neuronal and hormonal alpha-adrenergic contraction. Mol. Pharmacol. 23, 570-575 (1983)

18 Barnes, P.J., Basbaum, C.B., Nadel, J.A., Roberts, J.M.: Pulmonary alpha-adrenoceptors: autoradiographic localization using $\left[{ }^{3} \mathrm{H}\right]$ prazosin. Eur. J. Pharmacol. 88, 57-62 (1983)

19 Anderson, A.A., Ashfield, D.J. and Goadby, P.: A comparison in vitro of guinea pig central and peripheral airways smooth muscle. $\mathrm{Br}$. J. Pharmacol. 72, 534P (1981)

20 Kapanci, Y., Assimacopoulos, A., Irle, C., Zwahlen, A. and Gabbiani, G.: 'Contractile 
interstitial cells' in pulmonary alveolar septa: A possible regulator of ventilation/perfusion ratio? J. Cell. Biol. 60, 375-392 (1974)

21 Drazen, J.M. and Schneider, M.W.: Comparative responses of tracheal spirals and parenchymal strips to histamine and carbachol in vitro. $\mathrm{J}$.
Clin. Invest. 61, 1441-1444 (1978)

22 Carswell, H. and Nahorski, S.R.: $\beta$-Adrenoceptor heterogeneity in guinea pig airways: comparison of functional and receptor labelling studies. Br. J. Pharmacol. 79, 965-971 (1983) 